\title{
PHENOTYPIC VARIATION OF HUMAN ANTITHROMBIN III IN NORMAL PLASMA: DETECTION BY ISOELECTRIC FOCUSING
}

\author{
Yoshio Kera, Kichihei Yamasawa, and Setsuo Komura \\ Department of Legal Medicine, Kyoto Prefectural University of Medicine, \\ Kyoto 602, Japan
}

\begin{abstract}
Summary Plasma AT-III exhibits a microheterogeneous form with pIs distributed over a narrow $\mathrm{pH}$ range by analytical agarose gel isoelectric focusing followed by immunofixation. Three new variants, each of which was the heterozygous state between the common and each variant components, were observed in a total 370 samples from unrelated healthy donors. These variants have at least normal activities of the thrombin inactivation in the presence of heparin, and their immunological antigen concentrations in plasma are in the normal range.
\end{abstract}

\section{INTRODUCTION}

Antithrombin III (AT-III) is the important blood coagulation inhibitor and inactivates thrombin and some of the activated coagulation factors. Recently, Borsodi and Narasimhan (1978) and Kera and Yamasawa (1982) have demonstrated the microheterogeneities of the purified or plasma AT-III by preparative or analytical isoelectric focusing. Several abnormalities of AT-III molecule have been reported in the cases of AT-III deficiencies (Sas et al., 1974, 1975, 1980; Brozović et al., 1978; Wolf et al., 1979; Matsuo et al., 1979; Williams and Murano, 1981). However, up to the present day, no variation of AT-III molecule in the normal plasma has been observed. In the present study, we first report the phenotypic variations of normal human plasma AT-III using analytical agarose gel isoelectric focusing followed by immunofixation. These variant molecules show normal levels in the biological (heparin cofactor) activity and the antigen concentration in plasma.

\section{MATERIALS AND METHODS}

EDTA-plasma (containing $5 \mathrm{~mm}$ trisodium EDTA) or citrated plasma (containing $13 \mathrm{~mm}$ trisodium citrate) were obtained from 370 unrelated healthy adult Japanese and stored at $-80^{\circ} \mathrm{C}$ until used. The methods of analytical agarose gel iso- 
electric focusing ( $\mathrm{pH} 4-6.5$ ) followed by immunofixation and the calibration of the isoelectric points (pIs) in the gel were described previously (Kera et al., 1981). Antihuman antithrombin III serum (rabbit) was purchased from Behringwerke AB, FRG. The biological (heparin cofactor) activity was measured by the amidolytic method using the Testzym ${ }^{\mathbb{R}}$ antithrombin assay kit (S-2238, Kabi Diagnostica, Sweden). The immunological AT-III concentration in plasma was determined by the technique of single radial immunodiffusion (Mancini et al., 1965). A series of diluted solutions of Protein-Standard-Plasma (containing $25 \mathrm{mg} \mathrm{AT-III/100} \mathrm{ml,} \mathrm{Behringwerke} \mathrm{AB)}$ was used for the calibration. All measurements were repeated in triplicate. One hundred $\mu$ l of plasma sample was treated with $1 \mathrm{U}$ neuraminidase from Arthobacter ureafaciens (Nakarai Chemicals Ltd., Japan) according to the previous study (Kera and Yamasawa, 1982).

\section{RESULTS AND DISCUSSION}

The immunofixation patterns of plasma AT-III after agarose gel isoelectric focusing were shown in Fig. 1. One of which was the common type (No. 1) and the others were three variant types (No. 2, 3, 4). 367 plasma samples in a total 370 samples from unrelated healthy donors showed the common type. The common type consisted 5 major and several minor bands with pIs between $\mathrm{pH} 4.8$ and 5.2. Each of variants seemed to have at least a bands-group of the common type and might be heterozygous state between the common and each new bands-group. These types of No. 1, 2, 3 and 4 were tentatively designated to be C-C (C, common), $\mathrm{C}-\mathrm{K}_{1}(\mathrm{~K}, \mathrm{Kyoto}), \mathrm{C}-\mathrm{K}_{2}$ and $\mathrm{C}-\mathrm{K}_{3}$, respectively. The $\mathrm{K}_{1}, \mathrm{~K}_{2}$ and $\mathrm{K}_{3}$ components were respectively shifted in pls from the $\mathrm{C}$ component toward the anode in $0.02-$ $0.03,0.05-0.06$ and $0.09-0.1 \mathrm{pH}$ unit.

Borsodi and Narasimhan (1978) reported that, after the neuraminidase treatment, purified human AT-III showed only a single, homogeneous peak by a preparative isoelectric focusing and one band by analytical isoelectric focusing. In the previous study (Kera and Yamasawa, 1982), although most of the original AT-III bands were reduced to 1 major band after the neuraminidase treatment, several minor bands were observed yet in the case of using immunofixation. As shown in Fig. 2 , after the neuraminidase treatment, the $\mathrm{C}-\mathrm{C}$ type which consisted 1 major ( $\mathrm{pI}=\mathrm{pH}$ 5.7) and several minor bands were observed at pIs between $\mathrm{pH} 5.5$ and 5.8. The $\mathrm{C}-\mathrm{K}_{1}$ type was not distinguished from the C-C type. The $\mathrm{C}-\mathrm{K}_{2}$ or the $\mathrm{C}-\mathrm{K}_{3}$ types had 2 major bands and one of which corresponded to the major band of the $\mathrm{C}$ component. The differences in pIs between these 2 major bands were calibrated to be about $0.1 \mathrm{pH}$ unit in the $\mathrm{C}-\mathrm{K}_{2}$ type and about $0.13 \mathrm{pH}$ unit in the $\mathrm{C}-\mathrm{K}_{3}$ type. Because the $\mathrm{K}_{2}$ or $\mathrm{K}_{3}$ components are discriminated from the $\mathrm{C}$ component after the neuraminidase treatment, these differences between 2 bands can not be explained by unequal contents of sialic acid residues. These differences may be due to the difference in polypeptide structures.

Jpn. J. Human Genet. 

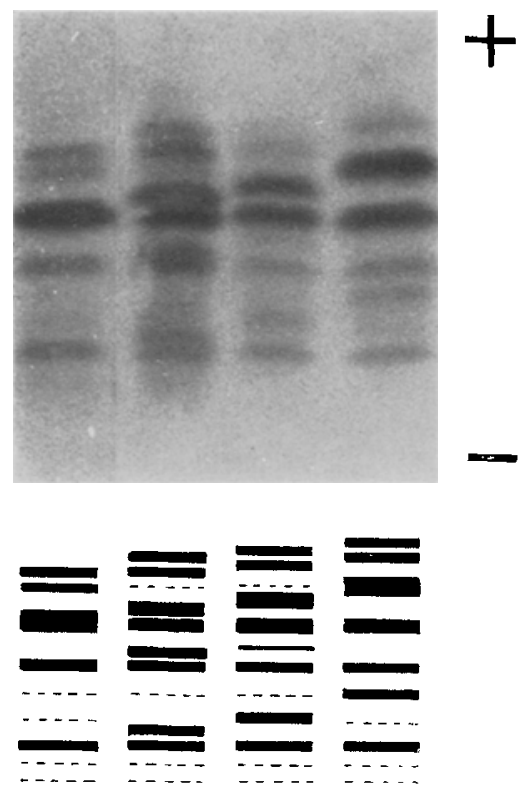

\section{$\begin{array}{llll}1 & 2 & 3 & 4\end{array}$}

Fig. 1. Photographic and shematic representations of plasma AT-III patterns after agarose gel isoelectric focusing followed by immunofixation. $1, \mathrm{C}-\mathrm{C} ; 2, \mathrm{C}-\mathrm{K}_{1} ; 3$, $\mathrm{C}-\mathrm{K}_{2} ; 4, \mathrm{C}-\mathrm{K}_{3}$.

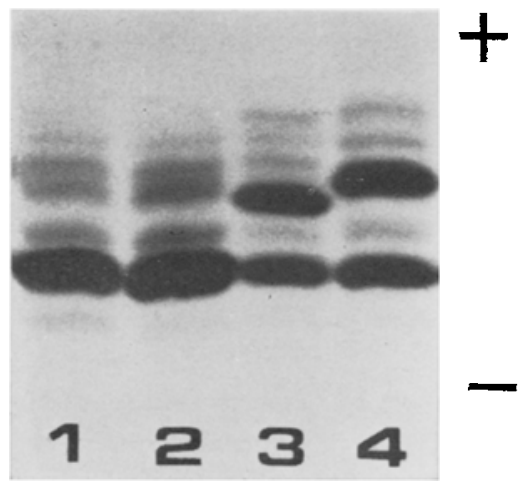

Fig. 2. Photographic representation of plasma AT-III patterns after agarose gel isoelectric focusing followed by immunofixation. All samples were treated with neuraminidase. $1, \mathrm{C}-\mathrm{C} ; 2, \mathrm{C}-\mathrm{K}_{1} ; 3, \mathrm{C}-\mathrm{K}_{2} ; 4, \mathrm{C}-\mathrm{K}_{3}$.

Several abnormalities of AT-III molecule were reported and their functional activities were significantly depressed (Sas et al., 1974, 1975, 1980; Brozovic̀ et al., 1978; Wolf et al., 1979; Williams and Murano, 1981). However, in the present

Vol. 28 , No. 4,1983 
Table 1. Plasma AT-III levels in normal blood donors.

\begin{tabular}{ccccc} 
Phenotype & No. of samples & $\begin{array}{c}\text { Activity } \\
(\mathrm{U} / \mathrm{ml})\end{array}$ & $\begin{array}{c}\text { Antigen } \\
\text { concentration } \\
(\mathrm{mg} / 100 \mathrm{ml}(\%))\end{array}$ & $\begin{array}{l}\text { Specific } \\
\text { activity } \\
(\mathrm{U} / \mathrm{mg})\end{array}$ \\
\hline C-C & 42 (pooled) & 1.00 & $25.8(100.0)$ & 3.88 \\
C-C & 1 & 0.96 & $26.4(102.3)$ & 3.64 \\
C-C & 1 & 1.20 & $28.8(111.6)$ & 4.17 \\
C-C & 1 & 1.27 & $32.8(127.1)$ & 3.87 \\
C-C & 1 & 1.02 & $28.3(109.7)$ & 3.60 \\
C-K & 1 & 1.37 & $37.2(144.2)$ & 3.68 \\
C-K & 1 & 1.13 & $27.3(105.8)$ & 4.14 \\
C-K & 1 & 1.01 & $27.6(107.0)$ & 3.66
\end{tabular}

a 1 unit of AT-IIl was tentatively defined to activity in $1 \mathrm{ml}$ of pooled plasma from healthy adult donors with the $\mathrm{C}-\mathrm{C}$ type. $\mathrm{b}$ Activity per milligram antigen protein.

study, the thrombin inhibition activities in the presence of heparin, AT-III concentrations and specific activities of these new types seemed to be in the normal ranges (Table 1).

Unfortunately, as familial materials could not be available, the inheritabilities of these variant components have not been demonstrated yet. However, the $\mathrm{K}_{2}$ or $\mathrm{K}_{3}$ components were not produced by at least postsynthetic modification as by unequal contents of sialic acid residues. Furthermore, these plasma samples, which were repeatedly obtained in the different day, always gave the identical patterns.

In the standpoint of examining abnormal or variant molecule of plasma ATIII, the techniques of analytical isoelectric focusing followed by immunofixation would give more prominent resolution in a comparison with the technique of modified crossed immunoelectrophoresis in the heparin-agarose, because these variant molecules were not discriminated from common component by the technique of modified crossed immunoelectrophoresis in the heparin-agarose.

\section{REFERENCES}

Borsodi, A., and Narasimhan, T.R. 1978. Microheterogeneity of human antithrombin III. Brit. J. Haematol. 39: 121-127.

Brozović, M., Stirling, Y., and Hamlyn, A.N. 1978. Thrombotic tendency and probable antithrombin deficiency. Thrombos. Haemostas. 39: 778-779.

Kera, Y., Nishimukai, H., and Yamasawa, K. 1981. Genetic polymorphism of the B subunit of human coagulation factor XIII: Another classification. Hum. Genet. 59: 360-364.

Kera, Y., and Yamasawa, K. 1982. Isoelectric focusing pattern of human antithrombin III (ATIII): Effects of heparin or thrombin on a microheterogeneous form of AT-III. Electrophoresis 3: 157-161.

Mancini, G., Carbonara, A.O., and Heremans, J.F. 1965. Immunochemical quantitation of antigens by single radial immunodiffusion. Int. J. Immunochem. 2: 235-254. 
Matsuo, T., Ohki, Y., Kondo, S., and Matsuo, O. 1979. Familial antithrombin III deficiency in a Japanese family. Thrombos. Res. 16: 815-823.

Sas, G., Blaskó, G., Bánhegyi, D., Jákó, J., and Pálos, L.Á. 1974. Abnormal antithrombin III (antithrombin III 'Budapest') as a cause of a familial thrombophilia. Thrombos. Diathes. Haemorrh. 32: 105-115.

Sas, G., Pepper, D.S., and Cash, D. 1975. Further investigations on antithrombin III in the plasmas of patients with the abnormality of 'antithrombin III Budapest.' Thrombos. Diathes. Haemorrh. 33: 564-572.

Sas, G., Petö, I., Bánhegyi, D., Blásko, G., and Domján, G. 1980. Heterogeneity of the "classical" antithrombin III deficiency. Thrombos. Haemostas. 43: 133-136.

Williams, L., and Murano, G. 1981. Human antithrombin III heterogeneity. Blood 57: 229-232.

Wolf, M., Boyer, C., Lavergne, J.M., and Larrieu, M.J. 1979. A new variant of antithrombin III. Study of three related cases. Thromos. Haemostas. 42: 186 (Abstract). 